\title{
LECCIONES DE DERECHO PROCESAL CIVIL* Alvarado Velloso, A., Punto Lex, Thomson Reuters, SANTIAGO, 2011. 844 PP.
}

Diego Palomo Vélez $Z^{* *}$

Me encontraba preparando el Seminario "Reforma procesal civil: cambio ad portas", que organizamos junto a la Asociación de Magistrados del Maule y el Instituto Panamericano de Derecho Procesal, cuando recibo una correo electrónico en el cual se me informaba de la publicación en Chile de una nueva obra ligada al Derecho procesal. Su autor, Adolfo Alvarado Velloso, destacado profesor argentino, presidente del IPDP, invitado principal del Seminario en comento.

En la señalada comunicación me señalan que se quiere realizar la presentación de esta obra en el marco del Seminario. Como parte de la organización hago los ajustes del caso para contemplar dentro del programa esta importante actividad. Cuando efectúo la consulta en torno a quién realizaría la presentación me indican que el autor pedía que el suscrito cumpliera ese cometido. Honrado acepté. En dos días recibí la obra: 844 pp. bajo el título "Lecciones de Derecho Procesal Civil", con la precisión de que se trata de un Compendio del Libro "Sistema Procesal: Garantía de la Libertad", adaptado a la Legislación nacional por el profesor Hugo Botto O.

No obstante tratarse de una obra extensa (casi 30 lecciones, 28 para ser preciso), que aborda prácticamente todos los grandes temas del Derecho Procesal Civil, su lectura no resulta farragosa; al contrario, permite avanzar en las distintas lecciones sin mayores inconvenientes, bajo una fórmula que mantiene al lector conectado con la explicación sistémica que se propone el autor. Entre las lecciones que recoge esta obra figuran: la causa y razón de ser del proceso: una aproximación a su idea lógica; las normas de procedimiento y su creación: el derecho procesal; los sistemas de enjuiciamiento; la acción procesal y la

\footnotetext{
* Colaboración recibida el 19 de agosto y aprobada el 20 de septiembre de 2011.

** Profesor de Derecho Procesal en la Facultad de Ciencias Jurídicas y Sociales de la Universidad de Talca; Doctor en Derecho, Universidad Complutense de Madrid. Correo electrónico: dpalomo@utalca.cl.
} 
reacción del resistente; la pretensión procesal; la jurisdicción; la competencia; el proceso como método; los principios y reglas procesales; la regularidad y la irregularidad procesal; las partes; el Juez; los terceros; la confirmación procesal; la acumulación procesal; la eficacia del proceso y la sentencia; el objeto del proceso: la sentencia; la ejecución procesal; la impugnación procesal; procedimiento cautelar.

Imposibilitado de referirme a cada una de las lecciones abordadas, creo que una referencia precisa al contenido de esta obra pasa por dos consideraciones. La primera de ellas liga con la fórmula que sigue para plantear los distintos temas, alejada de lo que la literatura procesal nacional ha acostumbrado hacer, salvo honrosas excepciones, muy en especial en los últimos años. El autor privilegia la explicación de la institución procesal para asegurar la comprensión del lector, que se puede hacer con ella con seguridades. Como puro complemento, por lo tanto esquivando la pura exégesis de la ley, se ofrece una referencia comentada a la situación normativa nacional que corresponde a cada una de las instituciones procesales analizadas, en un esquema de trabajo que se repite en las publicaciones que de esta obra se ha hecho en otros países de América Latina. Esta labor de complementación y adaptación la realizó el chileno Hugo Botto O., Doctor en Derecho Procesal por la Universidad de Rosario, uno de los representantes nacionales más conocidos de la Escuela procesal generada a partir de las enseñanzas de Alvarado Velloso en Rosario, Argentina.

La segunda consideración entronca derechamente con su contenido. La obra no recoge a nuestro juicio explicaciones particulares de cada tema o institución como si se tratara de compartimentos estancos sin vinculación. Lo que hace el autor es postular y explicar las consecuencias de un verdadero sistema procesal, que él denomina sistema procesal garantista, y opone al sistema publicista. El lector podrá constatar las distintas respuestas que ambos sistemas han dado frente al problema o crisis de la Justicia civil, en una explicación del autor que aborda aspectos históricos, de actualidad y de futuro.

¿Qué reivindica el sistema garantista? Fundamentalmente, de acuerdo a lo que se lee a lo largo de la obra, el "método" en que consiste el proceso, como mecanismo de solución pacífica de las controversias de relevancia jurídica, cuya legitimidad no puede ser sacrificada bajo la excusa de la "meta". Para el autor este sacrificio nos expone al subjetivismo y decisionismo judicial, que muy serios perjuicios a aparejado al sistema judicial en su país. De acuerdo a lo que podría interpretarse tras la lectura de la obra, la meta importa, pero no a cualquier costo: el fin no justificaría los medios.

En la perspectiva recién anotada, Alvarado Velloso distingue con acierto entre principios y reglas procesales, cuestión que a nuestro juicio le permite explicar bien la base de las distintas respuestas que la Escuela garantista y publicista dan a la crisis de la Justicia civil. Para la primera los principios pro- 
cesales (los verdaderos principios) son un puñado de postulados elementales que, por mandato constitucional y de los tratados internacionales de derechos fundamentales, no pueden faltar en el diseño de un proceso, de un verdadero proceso. Habla por ejemplo de la imparcialidad del tribunal, la igualdad de las partes, la transitoriedad del proceso, la eficacia de la serie procedimental, y la moralidad en el debate. Sin ellos, explica el autor, estaríamos frente a un simulacro de proceso, y no frente a un verdadero proceso.

Si bien la explicación de Alvarado Velloso hunde sus raíces en cada una de las instituciones que trata en esta obra, donde más se aprecian las consecuencias del sistema que postula es en la noción de la función jurisdiccional, del proceso y especialmente de la prueba, que el prefiere llamar confirmación procesal. Es precisamente en este punto donde las diferencias con la Escuela publicista se hacen más evidentes, y en donde la finalidad de la prueba y los protagonismos reconocidos a las partes y a los jueces no coinciden.

Alvarado Velloso plantea y sostiene una explicación que podrá o no compartirse, pero que busca la coherencia de un sistema. Nuestra realidad legislativa, especialmente en América Latina, muestra una situación diversa, bastante influenciada por la Escuela publicista, en donde se reconocen amplios poderes a los jueces en la idea que a partir de esta asignación de potestades judiciales podrá mejorarse, de verdad, una Justicia civil que no responde a las necesidades de los ciudadanos. Se ha instalado la idea de que los jueces deben hacer justicia a pesar de los abogados, considerados un estorbo para una respuesta que sea justa y oportuna, lo que justificaría unas regulaciones procesales que a la asignación de facultades judiciales oficiosas no acompaña los necesarios resguardos a los derechos de las partes. Se comienza, además, a reconocer como elemento central de la eficiencia de los nuevos modelos reformados la celeridad procesal, en un afán que viene brindando un peligroso protagonismo a las estadísticas más que a la calidad de la respuesta jurisdiccional. En definitiva, parece conveniente buscar fórmulas que junto con apostar por la justicia de la decisión, como pretenden serlo aquéllas empleadas por nuestro legislador en las últimas reformas procesales (Justicia de familia y del trabajo entre ellas), logren un adecuado equilibrio con el necesario respeto que deben tener aquéllos postulados básicos que deben ser cautelados en todo proceso que se aprecie como tal.

Esta obra brinda una lectura distinta de lo que debe ser un proceso (legítimo) que vale tener a la vista, en especial en momentos en que se está trabajando en una nueva legislación procesal civil que deberá levantarse en unos principios que respondan a la esencia que cabe reconocer en todo (debido) proceso. 
